\title{
How to Design Economic Predictive Laboratory Panel Evaluating Acute Ischemic Stroke Outcome
}

\author{
Hasnaa A. Abo-Elwafa1 ${ }^{*}$, Hazem K. Ibrahim², Hassan M. El-Nady², Asmaa H. Abbas ${ }^{2}$ \\ ${ }^{1}$ Clinical Pathology, Faculty of Medicine, Sohag University, Sohag, Egypt \\ ${ }^{2}$ Neurology Department, Faculty of Medicine, Sohag University, Sohag, Egypt \\ Email: *Hasnaa_aboalwafa@med.sohag.edu.eg
}

How to cite this paper: Abo-Elwafa, H.A., Ibrahim, H.K., El-Nady, H.M. and Abbas, A.H. (2019) How to Design Economic Predictive Laboratory Panel Evaluating Acute Ischemic Stroke Outcome. Neuroscience \& Medicine, 10, 1-14.

https://doi.org/10.4236/nm.2019.101001

Received: October 20, 2018

Accepted: January 11, 2019

Published: January 14, 2019

Copyright $\odot 2019$ by author(s) and Scientific Research Publishing Inc. This work is licensed under the Creative Commons Attribution-NonCommercial International License (CC BY-NC 4.0). http://creativecommons.org/licenses/by-nc/4.0/

\section{Open Access}

\begin{abstract}
Background: acute ischemic stroke (AIS) remains the third cause of death and disability, and acute phase responses, both increasing international normalized ratio (INR) and activated partial thromboplastin time (APTT) are associated with worse outcome. Erythrocyte sedimentation rate (ESR) serves as severity marker, and non-fasting triglycerides (TG) indicates remnants of chylomicrons and very low density lipoproteins potentially pro-inflammatory. Aims: to design predictive economic panel evaluating AIS. Patients and methods: 100(AIS) patients were included, clinically evaluated by Scandinavian Stroke Scale (SSS) and Modified Rankin Score (MRS), subjected to complete blood count (CBC) on Cell-Dyne3700, manual ESR, INR and APTT on SYSMEX-CA1500, serum uric acid (SUA), serum albumin and non-fasting (TG) on Beckman Coulter AU480. Statistical analysis: STATA intercooled version 9.2. Results: odd ratio (OR), confidence interval (CI) of (MRS) in correlation to WBCs count in quartile (Q)3, 4 (OR 8.14, CI 2.29 - 8.90, significant $\mathrm{P}=0.01$; and OD13.5, CI 3.39 - 53.68, high significant $\mathrm{P}=0.001$ respectively), to APTT in Q3 (OD 4.15, CI $1.09-15.82, \mathrm{P}=0.04$ ), SUA in Q3 (OD 0.19 , CI $0.05-0.68, \mathrm{P}=0.01$ ), $\mathrm{TG}$ in $\mathrm{Q} 3,4$ (OD $0.24 \mathrm{CI} 0.06-0.88, \mathrm{P}=0.03$; and OD 0.09 , CI $0.02-0.34 \mathrm{P}=0.001$ respectively) and serum albumin in Q3(OD 0.13, CI $0.04-0.51, \mathrm{P}=0.003$ ), insignificant correlations to ESR, INR and platelets. Conclusion: according to (MRS), the economic predictive panel should be included WBCs, APTT, SUA, and non-fasting TG with serum albumin as prognostic tool evaluating functional disability in AIS.
\end{abstract}

\section{Keywords}

Acute Ischemic Stroke, Predictive Laboratory Panel 


\section{Introduction}

Stroke is a leading cause of preventable death and major disability. Biomarkers are tests that indicate the physiology of the body [1]. Many biomarkers are related to the etiology and pathophysiology of the ischemic stroke as tissue ischemia markers, thrombosis and vascular occlusion markers, inflammatory response markers, arterial recanalization markers, biomarkers of early neurological deterioration, biomarkers of infarction size and outcome, and lastly biomarkers of preventive therapy [2]. The rapid and effective management of critically ill patients depends on rapid evaluation of the stroke etiology and clinical condition. This is necessary to take prompt decision in therapy especially when time of onset is not known [3]. SSS used in several clinical trials to either select patients or rate outcome severity [4]. Other tests are non-disease specific to brain ischemia, but can be applicable in assessing the stroke severity and can predict the outcome [5]. In practice guidelines of biomarkers panels used in AIS management are limited and meta-analysis studying of various stroke biomarkers has improve the evaluation of individual pathophysiology, promoting the establishment of screening panels for high risk patients, and rational therapy tailored to each patient findings [6]. Inflammatory parameters ESR and fibrinogen have been proposed as risk markers [7]. Leukocytes may reflect the inflammatory status after AIS, so it is considered as strategy to improve the outcome of the patient [8]. Some studies showed that, the pro-inflammatory biomarkers in association with high serum lipids and prothrombotic factors predispose to internal carotid artery occlusion [9] [10]. Increased level of biomarkers of inflammation and coagulation is associated with recurrent ischemic lesions after AIS [11]. The significant value of INR and APTT is a predictive risk factor for AIS outcome [12]. In patients diagnosed as AF with long term warfarin therapy, INR is not considered as a predictive test for AIS outcome, but D-dimer is used instead [13] [14]. Ischemic modified albumin is considered as a useful diagnostic marker of both AIS, and its sensitivity and specificity is 87\% [15] [16]. Another chemical investigation within the predictive panels of AIS is SUA. Its high level is associated with excellent outcomes so it used as adjuvant therapy to thrombolysis [17] [18]. Serum TG is an independent predictor of AIS outcome, but its association with cardio-embolic stroke is not a role [19]. Increase level of non-fasting triglycerides is associated with increasing risk of ischemic stroke [20].

\section{Patients and Methods}

\subsection{Study Protocol}

The study was carried out on 100 patients admitted to Neurology Department, Sohag University Hospital, over a period of one year from May 2013 to May 2014, they were diagnosed as AIS. Their age ranged from 27 to 88 years old with median age 65 years; they were 52 males and 48 females. The inclusion criteria were diagnosis of AIS, according to the definition established by the World Health Organization, stroke is rapidly developed clinical signs of focal or global 
deficits of cerebral function, lasting more than 24 hours, or until death, with no apparent non-vascular cause [1]. The exclusion criteria were other ischemic conditions like acute myocardial infarction, limb ischemia, and renal failure, known inflammatory or malignant disease, also cerebral hemorrhage or other coagulation disorders.

\subsection{Medical Ethics}

Institutional Research Committee Board had been approved the research. Informed consent from the enrolled patients or their relatives was obtained.

\subsection{Clinical Evaluation}

For each patient full history, clinical and neurological examination and brain computed tomography (CT scan) or magnetic resonance imaging (MRI), were performed within $24 \mathrm{~h}$ of stroke. The volume of hypo dense areas of brain CT scan, was calculated according to the formula based on length $\times$ depth $\times$ height $\times 1 / 2$ (in $\mathrm{mm}$ ) as in Figures 1-3. Stroke severity on admission was assessed using SSS, milder stroke was considered when SSS > 25 whereas it's considered

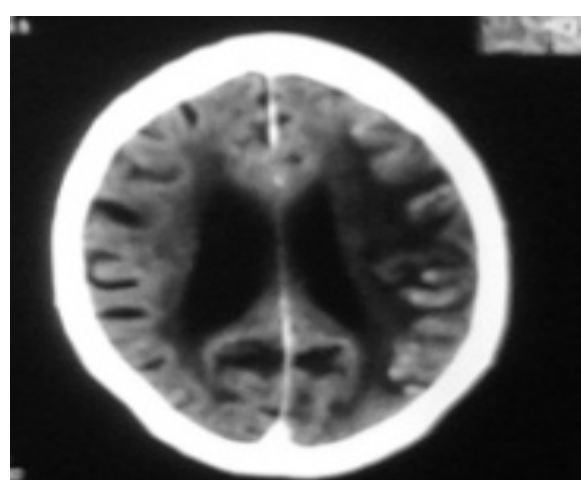

(a)

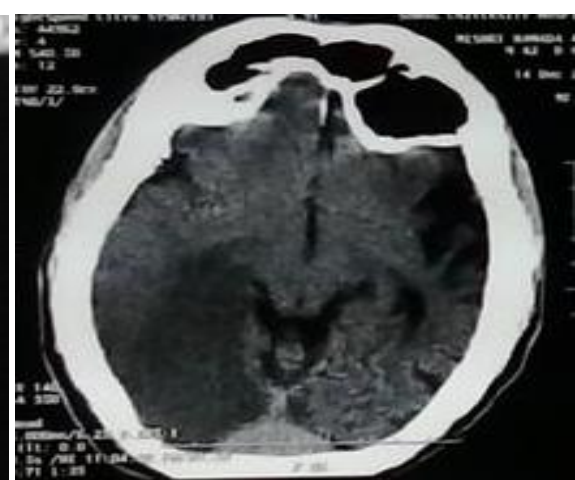

(b)

Figure 1. CT findings. (a) Lt cerebral infarction $1.6 \times 2.4 \mathrm{~cm}$; (b) Rt occipital infarction 5 $\times 4.5 \mathrm{~cm}$.

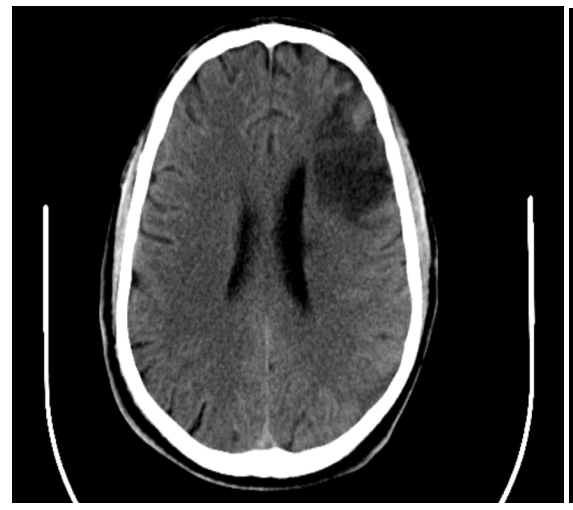

(a)

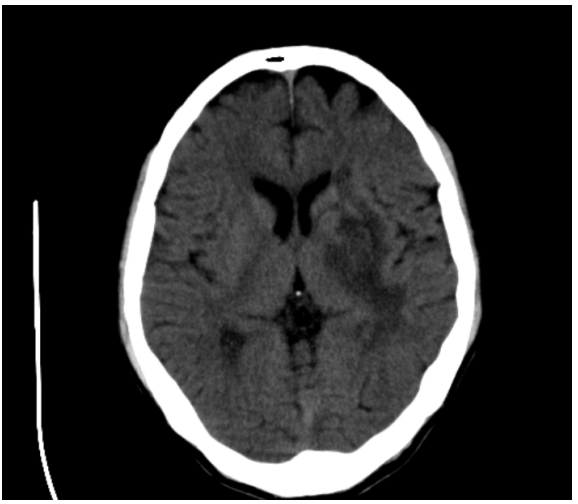

(b)

Figure 2. CT findings. (a) LT Frontal infarction $3 \times 3.6 \mathrm{~cm}$; (b) LT Basal ganglia infarction $3 \times 2.4 \mathrm{~cm}$. 


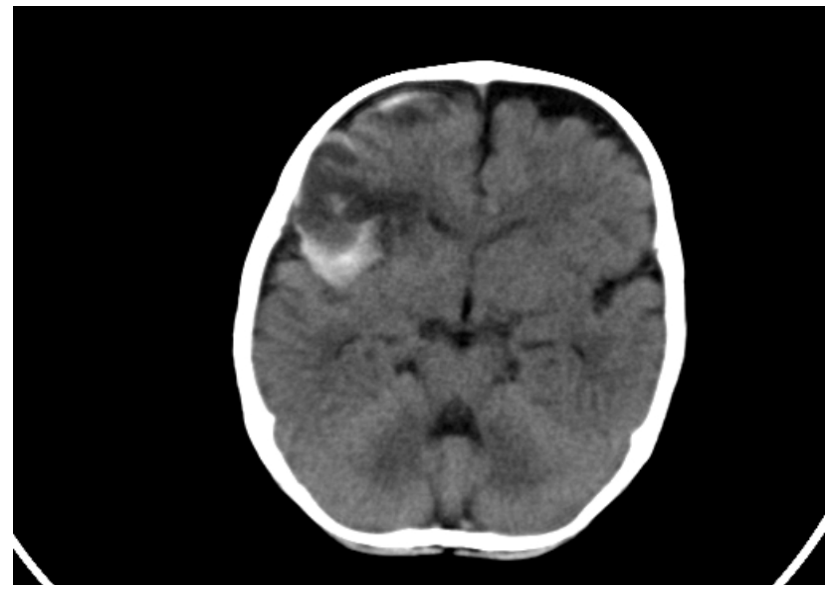

Figure 3. RT. Frontoprietal old infarction $4 \times 3.7 \mathrm{~cm}$.

more severe when SSS was $\leq 25$ [4]. Functional outcome was measured using MRS on day seven; lesser degree of disability was defined as MRS of $1-3$ whereas greater degree of disability was defined as MRS 4 - 6 [1]. Hypertension was defined as diastolic blood pressure (DBP) $\geq 90 \mathrm{mmHg}$ and/or a systolic blood pressure (SBP) $\geq 140 \mathrm{mmHg}$. Diabetic patients were considered when fasting blood glucose is more than $126 \mathrm{mg} / \mathrm{dl}$ or random blood glucose is more than $200 \mathrm{mg} / \mathrm{dl}$.

\section{Laboratory Investigations}

Sample processing: $7 \mathrm{ml}$ of venous blood (non-fasting sample) was withdrawn from each patient, divided as follow: $2 \mathrm{ml}$ was delivered into trisodium citrate vacutainer; which centrifuged at $3000 / \mathrm{rpm}$ for $10 \mathrm{~min}$ at $18^{\circ} \mathrm{C}-22^{\circ} \mathrm{C}$ to separate platelet poor plasma (P.P.P) used for INR and aPTT, another $3 \mathrm{ml}$ of blood was delivered into K-EDTA vacutainer used for $\mathrm{CBC}$ and then diluted 4:1 with trisodium citrate solution (3.2\%) used for ESR, the remaining blood was clotted, then centrifuged at $3000 / \mathrm{rpm}$ for $5-10 \mathrm{~min}$, at room temperature, the separated serum was used for the remaining investigations.

\section{Methods}

CBC was performed on the Abbott Cell-Dyne 3700, (USA) automated hematology analyzer. ESR was performed using Westergren's method; the reading was adjusted to the $1^{\text {st }}$ hour. INR and aPTT were determined using the Sysmex-CA1500 System (Germany) fully automated blood coagulation analyzer; the reagents were SIEMENS' Thromborel'S,Cat.No.OUHP29/54690523, Pathrombtin SLCat.No.OQGS29/53667823). Renal function tests including SUA, liver function tests with serum albumin, blood glucose and non-fasting TG were performed on Beckman Coulter AU480 (USA) fully automated system; all reagents were supplied by Coulter Beckman.

\section{Statistical Analysis}

Data was analyzed using STATA intercooled version 9.2. The data were not 
normally distributed; Mann-Whitney test was used. Evaluation of the data was by definition of mean $\pm \mathrm{SD}$. Logistic regression analysis was used to calculate Odds Ratio and 95\% Confidence interval (OR and 95\% CI), threshold for statistical significance was established at $\mathrm{P}<0.05$.

\section{Results}

This study was performed over one year from 2013- to 2014 on 100 patients admitted to University Hospital, Neurology Department, diagnosed as AIS; their mean age was $64.83 \pm 11.58$ years old, males to females' ratio was 52/48. As regard the risk factors twenty patients $(20 \%)$ were smokers, sixty two $(62 \%)$ were hypertensive, the diabetic cases were 29 (29\%), and cardiac patients were 48 (48\%), one third of them were atrial fibrillation (AF) sixteen patients. Thirty three patients (33\%) had positive history of previous attack. These data were presented in Table 1. The neurological data of studied population showed that the Glasgow Coma Scale (GCS) was $11.84 \pm 2.75$ and median was 11, GCS was $\geq 8$ in 89 patients $(89 \%)$, where it was $<8$ in eleven patients (11\%). stroke severity using (SSS), mean \pm SD was $23.69 \pm 17.52$ and median was 17.5 . The disability scale at discharge by (MRS), was $3.86 \pm 1.37$ and median was 4 , MRS was $\geq 3$ in $38 \%$ of patients, where as it was $<3$ in $62 \%$ of patients. CT scan was normal in

Table 1. Patients' characteristics and risk factors.

\begin{tabular}{|c|c|}
\hline Items & Statistics \\
\hline \multicolumn{2}{|l|}{ Age in years } \\
\hline Median (range) & $65(27-88)$ \\
\hline \multicolumn{2}{|l|}{ Sex } \\
\hline Females/males & $48 / 52$ \\
\hline Risk Factors & (No. and \%) \\
\hline \multicolumn{2}{|l|}{ Smoking } \\
\hline No & 80 \\
\hline Yes & 20 \\
\hline \multicolumn{2}{|l|}{ Previous stroke } \\
\hline No & 67 \\
\hline Yes & 33 \\
\hline \multicolumn{2}{|l|}{ Hypertension } \\
\hline No & 38 \\
\hline Yes & 62 \\
\hline \multicolumn{2}{|l|}{ Diabetes } \\
\hline No & 71 \\
\hline Yeas & 29 \\
\hline \multicolumn{2}{|l|}{ Cardiac } \\
\hline No & 52 \\
\hline Ischemic & 32 \\
\hline $\mathrm{AF}$ & 16 \\
\hline
\end{tabular}


forty one (41\%) of studied population, while it revealed ischemic changes in nine patients (9\%), old infarction in seven patients (7\%), recent infarction in 39 cases (39\%) and multiple lacunae's in $4 \%$ of them (Figures 1-3). Comparison between patients with mild or moderate to those with severe SSS at admission according to the tested panel, we find that; in patients with less severe stroke (SSS > 25); ESR was $26.51 \pm 21.67 \mathrm{~mm} / \mathrm{h}$, total WBCs was $(8.89 \pm 3.69) \times 10^{9} / \mathrm{l}$, neutrophils was $(6.23 \pm 3.58) \times 10^{9} / 1$, platelets count was $(276.64 \pm 91.76) \times 10^{9} / \mathrm{l}$, INR was $1.13 \pm 0.15$, aPTT was $31.30 \pm 5.19$ Sec., serum uric acid was $6.67 \pm 2.26 \mathrm{mg} / \mathrm{dl}$, non-fasting triglycerides was $168.72 \pm 120.27 \mathrm{mg} / \mathrm{dl}$ and serum albumin was 3.53 $\pm 0.53 \mathrm{~g} / \mathrm{dl}$. while in patients with more severe stroke (SSS $\leq 25$ ); ESR was 27.28 $\pm 22.51 \mathrm{~mm} / \mathrm{h}$, WBCs was $(11.94 \pm 4.42) \times 10^{9} / \mathrm{l}$, neutrophils was $(9.78 \pm 6.46) \times$ $10^{9} / \mathrm{l}$, platelets was $(270.07 \pm 92.13) \times 10^{9} / \mathrm{l}$, INR was $1.13 \pm 0.09$, aPTT was 33.16 $\pm 6.23 \mathrm{Sec}$., serum uric acid was $6.96 \pm 3.43 \mathrm{mg} / \mathrm{dl}$, non-fasting TG was $124.11 \pm$ $73.81 \mathrm{mg} / \mathrm{dl}$, serum albumin was $3.49 \pm 0.71 \mathrm{~g} / \mathrm{dl}$. The difference between these two groups was statistically highly significant for WBCs count $(P=0.001)$, neutrophils count $(P=0.004)$, and significant for triglycerides $(P=0.04)$. While it was insignificant for ESR $(P=0.77)$, platelets count $(P=0.42)$, INR $(P=0.64)$, aPTT $(\mathrm{P}=0.11)$, uric acid $(\mathrm{P}=0.89)$ and serum albumin $(\mathrm{P}=0.31)$. Given the random variance among AIS patients to the investigated panel; the OR of test's quartiles (Qs) demonstrated that, (Q1) was used as reference to other quartiles (Q2), (Q3), (Q4)), when these (Qs) were assessed according to SSS; the resulting data were demonstrated in Table 2. In comparing patients with good to those with poor outcome according to MRS; the functional disability showed that 38 patients had good prognosis with score less than 3 in day seven, while the other 62 patients had bad prognosis in which the MRS was more than 3 by the day seven. The difference between these two groups was presented in Table 3. The OR of functional disability according to the MRS in relation to the random variance quartiles of investigated panel were presented in Table 4.

\section{Discussion}

Because stroke constitutes a major health problem not only affect the patient but also his/her family, and productive availability of the community especially if the affected patients within the adult age group, or even the old age group who need much care. So the accurate diagnosis with appropriate treatment can offer beneficial outcome with less severe disability. Design an economic panel predicting functional disability which is a common AIS squeals', is considered a strategic decision in hospital management programs to safe time, money and efforts, also provides the patients with the most suitable therapy within the target period for excellent functional discharge. Some researcher has reported stroke is a leading cause of death and adult disability [21]. Cerebral ischemia with subsequent reperfusion initiates an inflammatory response with increase in leukocytes, platelets and acute-phase proteins. With the elevated plasma viscosity and pronounced reduction in cerebral circulation; infarction size is increased as mentioned by Lakshmi 
Table 2. Odds ratio (95\% Confidence interval) in $1^{\text {st }}$ quartile of SSS to the laboratory panel.

\begin{tabular}{|c|c|c|}
\hline Item & Odds ratio (95 Confidence interval) & P-values \\
\hline \multicolumn{3}{|l|}{$\mathrm{ESR} \mathrm{mm} / \mathrm{h}$} \\
\hline $\mathrm{Q} 1(2-9, \mathrm{n}=25)$ & 1 & \\
\hline Q2 $(11-20, \mathrm{n}=25)$ & $1.00(0.33-3.06)$ & 1.00 \\
\hline Q3 $(23-37, \mathrm{n}=25)$ & $1.18(0.38-3.63)$ & 0.78 \\
\hline $\mathrm{Q} 4(37-97, \mathrm{n}=25)$ & $1.00(0.33-3.06)$ & 1.00 \\
\hline \multicolumn{3}{|l|}{ WBCs $\times 10^{9} / 1$} \\
\hline $\mathrm{Q} 1(4.16-7.7, \mathrm{n}=25)$ & 1 & \\
\hline Q2 $(7.8-9.7, \mathrm{n}=25)$ & $3.43(1.03-11.48)$ & $0.045 \mathrm{~S}$ \\
\hline Q3 $(9.8-12.5, \mathrm{n}=25)$ & $8.14(2.29-28.90)$ & $0.001 \mathrm{HS}$ \\
\hline $\mathrm{Q} 4(12.9-28.3, \mathrm{n}=25)$ & $12.67(3.31-48.50)$ & $<0.0001 \mathrm{HS}$ \\
\hline \multicolumn{3}{|l|}{ Platelets $\times 10^{9} / 1$} \\
\hline Q1 $(175-207, \mathrm{n}=25)$ & 1 & \\
\hline Q2 $(208-259, \mathrm{n}=25)$ & $1.00(0.32-3.17)$ & 1.00 \\
\hline Q3 $(260-320, \mathrm{n}=25)$ & $0.44(0.14-1.37)$ & 0.16 \\
\hline $\mathrm{Q} 4(323-570, \mathrm{n}=25)$ & $0.72(0.23-2.23)$ & 0.56 \\
\hline \multicolumn{3}{|l|}{ INR } \\
\hline Q1 $(0.96-1.06, \mathrm{n}=26)$ & 1 & \\
\hline Q2 $(1.07-1.12, \mathrm{n}=26)$ & $1.17(0.39-3.50)$ & 0.78 \\
\hline Q3 $(1.13-1.18, \mathrm{n}=23)$ & $1.33(0.43-4.16)$ & 0.62 \\
\hline $\mathrm{Q} 4(1.19-1.91, \mathrm{n}=25)$ & $1.09(0.36-3.29)$ & 0.88 \\
\hline \multicolumn{3}{|l|}{ aPTT (sec) } \\
\hline Q1 (24.4 - 28, n = 25) & 1 & \\
\hline Q2 (28 - 31.7, n = 28) & $1.08(0.37-3.19)$ & 0.88 \\
\hline $\mathrm{Q} 3(32-35, \mathrm{n}=22)$ & $2.89(0.85-9.81)$ & 0.09 \\
\hline $\mathrm{Q} 4(35.7-58.8, \mathrm{n}=25)$ & $1.63(0.53-4.98)$ & 0.40 \\
\hline \multicolumn{3}{|l|}{ Uric acid (mg/dl) } \\
\hline Q1 $(1.4-4.6, \mathrm{n}=24)$ & 1 & \\
\hline Q2 $(4.8-6.1, \mathrm{n}=26)$ & $0.59(0.18-1.90)$ & 0.38 \\
\hline Q3 $(6.2-8.5, \mathrm{n}=22)$ & $0.29(0.08-0.96)$ & $0.04 \mathrm{~S}$ \\
\hline $\mathrm{Q} 4(8.6-17.7, \mathrm{n}=28)$ & $1.14(0.33-3.90)$ & 0.83 \\
\hline \multicolumn{3}{|l|}{ Triglyceride (mg/dl) } \\
\hline $\mathrm{Q} 1(61-84, \mathrm{n}=27)$ & 1 & \\
\hline $\mathrm{Q} 2(85-121, \mathrm{n}=23)$ & $0.79(0.24-2.60)$ & 0.70 \\
\hline Q3 $(122-160, n=26)$ & $0.42(0.14-1.30)$ & 0.13 \\
\hline $\mathrm{Q} 4(172-553, \mathrm{n}=24)$ & $0.30(0.09-0.95)$ & $0.04 \mathrm{~S}$ \\
\hline \multicolumn{3}{|l|}{ Albumin (g/dl) } \\
\hline Q1 $(2.3-3, \mathrm{n}=25)$ & 1 & \\
\hline $\mathrm{Q} 2(3.1-3.5, \mathrm{n}=32)$ & $0.53(0.18-1.58)$ & 0.26 \\
\hline Q3 $(3.6-3.8, \mathrm{n}=20)$ & $0.47(0.14-1.58)$ & 0.22 \\
\hline $\mathrm{Q} 4(3.9-6.4, \mathrm{n}=23)$ & $0.61(0.19-1.98)$ & 0.41 \\
\hline
\end{tabular}

S Significant $\mathrm{P}$ value $<0.05$, HS high significant $\mathrm{P}$-value 0.001 . 
Table 3. Modified Rankin Score between good and poor outcome in relation to the investigation panel.

\begin{tabular}{|c|c|c|c|}
\hline \multirow[b]{2}{*}{ Variables } & \multicolumn{2}{|c|}{ Modified Rankin score } & \multirow[b]{2}{*}{$\mathrm{P}$-values } \\
\hline & $\begin{array}{c}\text { Good outcome } \leq 3 \\
\text { no. }=38\end{array}$ & $\begin{array}{c}\text { Poor outcome }>3 \\
\text { no. }=62\end{array}$ & \\
\hline \multicolumn{4}{|l|}{$\mathrm{ESR} \mathrm{mm} / \mathrm{h}$} \\
\hline Mean \pm SD & $24.05 \pm 21.56$ & $29.26 \pm 22.29$ & 0.18 \\
\hline \multicolumn{4}{|l|}{$\mathrm{WBCs} \times 10^{9} / 1$} \\
\hline Mean \pm SD & $8.55 \pm 3.03$ & $11.90 \pm 4.59$ & $<0.001 \mathrm{~S}$ \\
\hline \multicolumn{4}{|l|}{ Platelets $\times 10^{9} / 1$} \\
\hline Mean \pm SD & $268.43 \pm 77.39$ & $275.63 \pm 99.76$ & 0.73 \\
\hline \multicolumn{4}{|l|}{ INR } \\
\hline Mean \pm SD & $1.11 \pm 0.09$ & $1.14 \pm 0.13$ & 0.10 \\
\hline \multicolumn{4}{|l|}{ aPTT Sec. } \\
\hline Mean \pm SD & $31.34 \pm 5.58$ & $32.99 \pm 5.97$ & 0.12 \\
\hline \multicolumn{4}{|l|}{ Uric acid mg/dl } \\
\hline Mean \pm SD & $6.78 \pm 1.94$ & $6.87 \pm 3.49$ & 0.32 \\
\hline \multicolumn{4}{|c|}{ Triglyceride mg/dl } \\
\hline Mean \pm SD & $176.4 \pm 105.9$ & $123.0 \pm 88.68$ & $0.005 \mathrm{~S}$ \\
\hline \multicolumn{4}{|c|}{ Serum albumin g/dl } \\
\hline Mean \pm SD & $3.59 \pm 0.47$ & $3.44 \pm 0.72$ & 0.06 \\
\hline
\end{tabular}

S Significant $\mathrm{P}$ value $<0.05$, HS high significant $\mathrm{P}$-value $<0.001$.

Table 4. Odds ratio in the $1^{\text {st }}$ quartile of Modified Rankin score in relation to investigation panel.

\begin{tabular}{|c|c|c|}
\hline Quartile of laboratory panel & Odds ratio ( $95 \%$ Confidence interval) & P-values \\
\hline \multicolumn{3}{|l|}{$\mathrm{ESR} \mathrm{mm} / \mathrm{h}$} \\
\hline $\mathrm{Q} 1(2-9, \mathrm{n}=25)$ & 1 & \\
\hline Q2 $(11-20, \mathrm{n}=25)$ & $1.64(0.53-5.09)$ & 0.39 \\
\hline Q3 $(23-37, \mathrm{n}=25)$ & $1.64(0.53-5.09)$ & 0.39 \\
\hline Q4 (37 - 97, n = 25) & $1.96(0.62-6.19)$ & 0.25 \\
\hline \multicolumn{3}{|l|}{$\mathrm{WBCs} \times 10^{9} / 1$} \\
\hline Q1 $(4.2-7.7, \mathrm{n}=25)$ & 1 & \\
\hline $\mathrm{Q} 2(7.8-9.7, \mathrm{n}=25)$ & $3.85(1.18-12.61)$ & 0.25 \\
\hline $\mathrm{Q} 3(9.7-12.5, \mathrm{n}=25)$ & $8.14(2.29-28.90)$ & $0.001 \mathrm{HS}$ \\
\hline $\mathrm{Q} 4(12.9-28.3, \mathrm{n}=25)$ & $13.5(3.39-53.68)$ & $<0.0001 \mathrm{HS}$ \\
\hline \multicolumn{3}{|l|}{ Platelets $\times 10^{9} / 1$} \\
\hline Q1 $(175-207, \mathrm{n}=25)$ & 1 & \\
\hline Q2 $(208-259, \mathrm{n}=25)$ & $0.58(0.18-1.91)$ & 0.37 \\
\hline $\mathrm{Q} 3(260-320, \mathrm{n}=25)$ & $0.42(0.13-1.36)$ & 0.15 \\
\hline $\mathrm{Q} 4(323-570, \mathrm{n}=25)$ & $0.69(0.21-2.85)$ & 0.55 \\
\hline \multicolumn{3}{|l|}{ INR } \\
\hline Q1 $(0.96-1.06, \mathrm{n}=26)$ & 1 & \\
\hline Q2 $(1.07-1.12, \mathrm{n}=26)$ & $1.00(0.34-2.98)$ & 1.00 \\
\hline Q3 $(1.13-1.18, \mathrm{n}=23)$ & $1.96(0.60-6.35)$ & 0.26 \\
\hline Q4 (1.19-1.91, $\mathrm{n}=25)$ & $2.20(0.69-7.06)$ & 0.18 \\
\hline
\end{tabular}




\section{Continued}

\begin{tabular}{|c|c|c|}
\hline aPTT (sec) & & \\
\hline Q1 $(24.4-28, \mathrm{n}=25)$ & 1 & \\
\hline Q2 $(28-31.7, \mathrm{n}=28)$ & $1.07(0.36-3.13)$ & 0.90 \\
\hline $\mathrm{Q} 3(32-35, \mathrm{n}=22)$ & $4.15(1.09-15.82)$ & $0.04 \mathrm{~S}$ \\
\hline $\mathrm{Q} 4(35.7-58.8, \mathrm{n}=25)$ & $1.64(0.53-5.09)$ & 0.39 \\
\hline \multicolumn{3}{|l|}{ Uric acid (mg/dl) } \\
\hline Q1 $(1.4-4.6, \mathrm{n}=24)$ & 1 & \\
\hline $\mathrm{Q} 2(4.8-6.1, \mathrm{n}=26)$ & $0.67(0.19-2.34)$ & 0.53 \\
\hline $\mathrm{Q} 3(6.2-8.5, \mathrm{n}=22)$ & $0.19(0.05-0.68)$ & $0.01 \mathrm{~S}$ \\
\hline $\mathrm{Q} 4(8.6-17.7, \mathrm{n}=28)$ & $0.63(0.18-2.21)$ & 0.47 \\
\hline \multicolumn{3}{|l|}{ Triglyceride (mg/dl) } \\
\hline Q1 $(61-84, \mathrm{n}=27)$ & 1 & \\
\hline $\mathrm{Q} 2(85-121, \mathrm{n}=23)$ & $0.40(0.10-1.59)$ & 0.19 \\
\hline Q3 $(122-160, \mathrm{n}=26)$ & $0.24(0.06-0.88)$ & $0.03 \mathrm{~S}$ \\
\hline $\mathrm{Q} 4(172-553, \mathrm{n}=24)$ & $0.09(0.02-0.34)$ & $<0.0001 \mathrm{HS}$ \\
\hline \multicolumn{3}{|l|}{ Albumin g/dl } \\
\hline $\mathrm{Q} 1(2.3-3, \mathrm{n}=25)$ & 1 & \\
\hline $\mathrm{Q} 2(3.1-3.5, \mathrm{n}=32)$ & $0.42(0.12-1.40)$ & 0.16 \\
\hline $\mathrm{Q} 3(3.6-3.8, \mathrm{n}=20)$ & $0.13(0.04-0.51)$ & $0.003 \mathrm{HS}$ \\
\hline $\mathrm{Q} 4(3.9-6.4, \mathrm{n}=23)$ & $0.47(0.13-1.72)$ & 0.25 \\
\hline
\end{tabular}

S: Significant P value $<0.05$, HS: high significant $\mathrm{P}$-value 0.001 .

et al. (2011) [22]. Within the findings of this study we noted that the age predominance of the patients was mostly around 6 and 7 decade of life, this in accordance with Scarborough et al., (2009); who reported the incidence of stroke increases rapidly with age [23]. The gender frequency in this work showed the male positive rate was $52 \%$ and the female positive rate was $48 \%$; these data are agree with Townsend (2012); who said it is approximately $25 \%$ higher in men than in women. But Zhou et al., (2013) found that women had worse outcomes [24] [25]. Biomarker panels can clarify the pathophysiological mechanisms of AIS and the approach to suitable therapy [26]. In this study, the elevated WBC count was associated with stroke severity at admission as noticed in SSS and more disability at discharge by MRS, these findings are in agreement with Peng et al., (2011) and Nardi et al., (2011) who noticed an increased WBC count at admission was significantly correlated to in-hospital death or disability later on [27] [28]. Also the demonstrated neutrophilia was adjuvant predictor correlated to how much the stroke is severe and the prognosis is bad as observed by SSS and MRS respectively. These results are in accordance with Pregl (2016) who reported that leukocytic count is useful marker for cerebral infarction [7]. ESR is an indicator of red blood cell aggregation, our findings however revealed neither the admission SSS nor the discharge MRS scores had a significant correlations with the ESR levels in AIS patients; this may be related to the small sample size of the patients or to the effects of hematocrit, plasma albumin levels, tempera- 
ture and anticoagulants as said by Lakshmi et al., (2011) [22]. Increased ESR may also have an indirect role in the formation of arterial thrombosis through its effects on the platelets [9] [22]. Kisialioul et al., (2012) had reported that circulating platelets has importance in AIS recurrence, because of its role not only depending on their direct effects on endothelium but also by acting as a connection for other cells in vascular system [29]. Platelet activation and aggregation are critically involved in the pathophysiology of atherosclerosis, thrombosis and ischemic stroke [30]. We didn't find any significant relation between stroke severity or outcome disability and platelet count for unexplained etiology. However, the impact of enhanced platelet activation in AIS on antithrombotic therapy had been established [24]. Coagulation and hemostatic markers are important in management of AIS patients [3]. In this work the results of aPTT were significantly associated with MRS in Q3, this denotes bad prognosis. Prolonged aPTT was associated with worse stroke outcome, suggesting it's neuro-protective effect at short time (Kisialioul et al., 2012) [29]. But the INR values in this study were not significantly associated with SSS or MRS, so INR can't be considered in the evaluation of AIS patients of this study, but it is more useful in monitoring thrombolytic therapy to avoid serious cerebral hemorrhage this opinion is in agree with Glushakova et al., (2016) and Pan et al., (2017) [3] [21]. Also in patient with AF on warfarin to prevent new lesions [31], Jickling et al., (2015) reported that, plasma lipids, proteins, RNA and other biomarkers had a utility in diagnosis and evaluation stroke [5]. Increased serum TG is associated with endothelial dysfunction, atherosclerosis and the production of a prothrombotic state, the non-fasting TG were associated with increasing risk of ischemic stroke these data were reported by Varbo et al. (2011) [20]. In our study the higher non-fasting TG the lower of stroke severity and discharge disability was found, this in accordance with the results Dziedzic, (2004) who had correlated the SSS to non-fasting TG levels within 36 hours of admission [32]. Others reported that higher fasting TG predicts less severe disability [33]. Another study had demonstrated that low serum TG is an independent predictor of mortality after cardio-embolic stroke [19]. Serum albumin is the most abundant protein found in plasma, acts as carrier molecule, and preserves oncotic pressure also antioxidant defender in inflammatory process [34]. Among the laboratory panel used we found that, the high normal serum albumin values were associated with less discharge disability by MRS.A study was done by Lu et al., (2012) showed a high-dose of human albumin, improving neurological status and reducing infarction size [35]. These are in agreement with our data in which low serum albumin was associated with elevated MRS at $7^{\text {th }}$ days, so albumin has neuro-protective mechanism. Ertekin et al. (2013) had reported that ischemic modified albumin represented a significant diagnostic value in AIS [15]. The role of SUA in AIS is still controversial, and a possible synergic role of SUA with thrombolytic therapies needs further investigations. Higher SUA levels in AIS patients receiving recombinant $\mathrm{t}-\mathrm{PA}$ have been associated with better outcome at 
day 90 and smaller infarct volume [18] [36]. In this study we noticed that, the elevated SUA was associated with less severe stroke and better outcome, so high SUA may be an independent predictor of AIS [17] [37]. All the discussed aspects of the laboratory procedures in AIS can postulate the importance of rapid and economic prognostic panel of investigations introduce as guidelines in practice during management the AIS patients. Limitations about this study were the small patients size may responsible the controversial results with other data, also lack of normal control in comparison due to illegibility to do brain CT or MRI to normal person, finally limited resources for follow up the infarction size at discharge.

\section{Conclusion}

The data of this work is necessitated the use of WBCs with differential neutrophils counted as independent outcome predictors as it has significant correlations to both SSS and MRS in the Q2, Q3, Q4, and APTT, which has a significant correlation to the MRS in Q3, also should be included. Both ESR and INR showed a non-significant correlation to both SSS and MRS so have no value as an adjuvant predictive tool for stroke outcome. Whereas the blood chemistry investigations mandate the use of serum albumin, non-fasting TG and SUA within the screening panel, they have a significant correlation to MRS in Q3, Q4 so considered as independent predictors for evaluating the functional disability of AIS patients. The small sample size in this work may be responsible for insignificant values of ESR and INR and platelets.

\section{Acknowledgements}

To doctor Nahla Hasan Assistant Prof. of Radiology Sohag University for her efforts in radiological diagnosis of the patients

\section{References}

[1] Peacock, W.F. (2016) Where Are Stroke Markers? 2016 by the American Association for Clinical Chemistry, Clinical Chemistry, Vol. 63, Issue 1.

https://doi.org/10.1373/clinchem.2016.255091

[2] Jickling, G.C. and Sharp, F.R. (2011) Blood Biomarkers of Ischemic Stroke. Neurotherapeutics, 8, 349-360.

[3] Glushakova, O.Y., Glushakova, A.V., Miller, E.R., Valadka, A.B. and Hayes, R.L. (2016) Biomarkers for Acute Diagnosis and Management of Stroke in Neurointensive Care Units. Brain Circulation, 2, 28-47.

[4] Barber, M., Fail, M., Shields, M., Stott, D.J. and Langhorne, P. (2004) Validity and Reliability of Estimating the Scandinavian Stroke Scale Score from Medical Records. Cerebrovascular Diseases, 17, 224-227. https://doi.org/10.1159/000075795

[5] Jickling, G.C. and Sharp, F.R. (2015) Biomarkers Panels in Ischemic Stroke. Stroke, 46, 915-920.

[6] Kim, S.J., Moon, J. and Bang, O.Y. (2013) Biomarkers for Stroke. Journal of Stroke, 15, 27-37. https://doi.org/10.5853/jos.2013.15.1.27 
[7] Pregl, V. (2016) Leucocyte Count Indicates Carotid Plaque Instability in Stroke Patients. Clinical and Experimental Pharmacology and Physiology, 73, 515-525.

[8] Tsai, N.W., Chang, W.N., Shaw, C.F., Jan, C.R. and Lu, C.H. (2010) Leucocyte Apoptosis in Patients with Acute Ischemic Stroke. Clinical and Experimental Pharmacology and Physiology, 37, 884-888. https://doi.org/10.1111/j.1440-1681.2010.05398.x

[9] Xie, D., Hu, D., Zhang, Q., Sun, Y., Li, J. and Zhang, Y. (2016) Increased High Sensitive CRP, ESR and Lactic Acid in Stroke Patients with Internal Carotid Artery Occlusion. Archives of Medical Science, 12, 546-551. https://doi.org/10.5114/aoms.2014.47879

[10] Singh, A.S., Atam, V., Yathish, B.E., Das, L. and Koonwar, S. (2014) Role of Erythrocyte Sedimentation Rate in Ischemic Stroke as an Inflammatory Marker of Carotid Atherosclerosis. Journal of Neurosciences in Rural Practice, 5, 40-45. https://doi.org/10.4103/0976-3147.127870

[11] Kang, D.W., Yoo, S.H., Chun, S., Kwon, K.Y., Kwon, S.U., Koh, J.Y. and Kim, J.S. (2009) Inflammatory and Hemostatic Biomarkers Associated with Early Recurrent Ischemic Lesions in Acute Ischemic Stroke. Stroke, 40, 1653-1658. https://doi.org/10.1161/STROKEAHA.108.539429

[12] Greuters, S., Van den Berg, A., Franschman, G., Viersen, V.A. and Beishuzen, A. (2011) Peerdeman SM and Boer C. Acute and Delayed Mild Coagulopathy Are Related to Outcome in Patients with Isolated Traumatic Brain Injury. Critical Care, $15, \mathrm{R} 2$.

[13] Nomura, E., Ohshita, T., Imamura, E., Wakabayashi, S., Hosomi, N. and Matsumoto, M. (2015) Early Administration of Non-Vitamin K Antagonist Oral Anticoagulants for Acute Ischemic Stroke Patients with Atrial Fibrillation in Comparison with Warfarin Mostly Combined with Heparin. Circulation Journal, 79, 862-866.

[14] Yamamoto, R., Nakae, Y., Tanaka, F. and Johkura, K. (2016) D-Dimer versus International Normalized Ratio of Prothrombin Time in Ischemic Stroke Patients Treated with Sufficient Warfarin. Journal of Stroke and Cerebrovascular Diseases, 25, 1781-1785.

[15] Ertekin, B., Kocak, S., Define Dundar, Z., Girisgin, S., Cander, B., Gul, M., Doseyici, S., Mehmetoglu, I. and Kemal Sahin, T. (2013) Diagnostic Value of Ischemic Modified Albumin in Acute Coronary Syndrome and Acute Ischemic Stroke. Pakistan Journal of Medical Sciences, 29, 1003-1007. https://doi.org/10.12669/pjms.294.3176

[16] Mehta, M.D., Marwah, S.A., Ghosh, S., Salah, H.N., Trivedi, A.P. and Haridas, N.A. (2015) Synergistic Role of Ischemic Modified Albumin and High Sensitivity Troponin in the Early Diagnosis of Acute Coronary Syndrome. Journal of Family Medicine and Primary Care, 4, 570-575.

[17] Liu, X., Liu, M., Chen, M., Ge, Q.M. and Pan, S.M. (2015) Serum Uric Acid Is Neuro-Protective in Chines Patients with Acute Ischemic Stroke Treated with Intravenous Recombinant Tissue Plasminogen Activator. Journal of Stroke and Cerebrovascular Diseases, 24, 1080-1086.

[18] Zhang, X., Huang, Z.C., Lu, T.S., You, S.J., Cao, Y.J. and Liu, C.F. (2016) Prognostic Significant of Uric Acid Level in Ischemic Stroke Patients. Neurotoxicity Research, 29, 10-20.

[19] Choi, K.H., Park, M.S. and Kim, J.T. (2012) Serum Triglyceride Level Is an Important Predictor of Early Prognosis in Patients with Acute Ischemic Stroke. Journal of the Neurological Sciences, 319, 111-116.

[20] Varbo, A., Nordestgaard, B.G., Tybjaerg-Hansen, A., Schnohr, P., Jensen, G.B. and 
Benn, M. (2011) Non-Fasting Triglycerides, Cholesterol, and Ischemic Stroke in the General Population. Annals of Neurology, 69, 628-634. https://doi.org/10.1002/ana.22384

[21] Pan, R., Yu, K., Weatherwax, T., Zheng, H., Liu, W. and Liu, K.J. (2017) Blood Occludin Level as Potential Biomarkers for Early Blood Brain Barrier Damage Following Stroke. Science Repots, 7, Article No. 40331.

[22] Lakshmi, A.B., Uma, P., Venkatachalam, C.H. and Nageswar Rao, G.S. (2011) A Simple Slide Test to Assess Erythrocyte Aggregation in Acute ST Elevated Myocardial Infarction and Acute Ischemic Stroke: Its Prognostic Significance. Indian Journal of Pathology and Microbiology, 54, 63-69. https://doi.org/10.4103/0377-4929.77327

[23] Scarborough, P.P., Bhatnagar, V.P., Kaur, L.A.J., Fernandez, L.R., Gray, A., Rayner, M. and Allender, S. (2009) Stroke Statistics. British Heart Foundation and Stroke Association, 44 .

[24] Townsend, N., Wickramasinghe, K., Bhatnagar, P., Smolina, K., Nichols, M., Leal, J., Fernandez, L.R. and Rayner, M. (2012) Coronary Heart Disease Statistics. British Heart Foundation and Stroke Association, 57.

[25] Zhou, G., Nie, S. and Dai, L. (2013) Sex Differences in Stroke Case Fatality: A MetaAnalysis. Acta Neurologica Scandinavica, 128, 1. https://doi.org/10.1111/ane.12091

[26] Whiteley, W., Wardlaw, J., Dennis, M., Lowe, G., Rumley, A., Sattar, N., Welsh, P., Green, A., Andrews, M. and Sandercock, P. (2012) The Use of Blood Biomarkers to Predict Poor Outcome after Acute Transient Ischemic Attack or Ischemic Stroke. Stroke, 43, 86-91. https://doi.org/10.1161/STROKEAHA.111.634089

[27] Peng, Y., Wang, D. and Zhang, J. (2011) Relationship between White Blood Cell Count at Admission and Short Term Outcome in Patients with Acute Cerebral Infarction. Clinical \& Investigative Medicine, 34, 249. https://doi.org/10.25011/cim.v34i4.15368

[28] Nardi, K., Milia, P. and Eusebi, P. (2011) Admission Leukocytosis in Acute Cerebral Ischemia: Influence on Early Outcome. Journal of Stroke and Cerebrovascular Diseases, 21, 819-824.

[29] Kisialiou, A., Pelone, G., Carrizzo, A., Grillea, G., Trimarco, V. and Marino, M. (2012) Blood Biomarkers Role in Acute Ischemic Stroke Patients: Higher Is Worse or Better?

[30] Zeller, J.A., Lenz, A., Tschoepe, D., Kessler, C. and Eschenfelder, C.C. (2005) Platelet Leukocyte Interaction and Platelet Activation in Acute Stroke with and without Preceding Infection. Arteriosclerosis, Thrombosis, and Vascular Biology, 25, 1519 1523. https://doi.org/10.1161/01.ATV.0000167524.69092.16

[31] Nomura, E., Ohshita, T., Imamura, E., Wakabayashi, S., Kajikawa, H. and Matsumoto, M. (2014) Can Early Effective Anticoagulation Prevent New Lesions on Magnetic Resonance Imaging in Acute Cardioembolic Stroke. Journal of Stroke and Cerebrovascular Diseases, 23, 2099-2104.

[32] Dziedzic, T., Slowik, A., Gryz, E.A. and Szczudlik, A. (2004) Lower Serum Triglyceride Level Is Associated with Increased Stroke Severity. Stroke, 35, e151-e152. https://doi.org/10.1161/01.STR.0000128705.63891.67

[33] Adibhatla, R.M. and Hatcher, J.F. (2008) Altered Lipid Metabolism in Brain Injury and Disorders. Subcellular Biochemistry, 49, 241-268. https://doi.org/10.1007/978-1-4020-8831-5_9

[34] Belayev, L., Liu, Y., Zhao, W., Busto, R. and Ginsberg, M.D. (2001) Human Albumin Therapy of Acute Ischemic Stroke. Marked Neuroprotective Efficacy at Mod- 
erate Doses and with a Broad Therapeutic Window. Stroke, 32, 553-560.

https://doi.org/10.1161/01.STR.32.2.553

[35] Lu, H.T., Zhao, J.G., Li, M.H. and Li, Y.D. (2012) Application of Albumin Prior to Delayed Thrombolysis Reduces Brain Edema and Blood Brain Barrier Permeability in an Embolic Stroke Model. Brain Research, 1438, 75-84.

[36] Amaro, S., Urra, X., Gomez-Choco, M., Obach, V., Cervera, A., Vargas, M., Torres, F., Rios, J., Planas, A.M. and Chamorro, A. (2011) Uric Acid Levels Are Relevant in Patients with Stroke Treated with Thrombolysis. Stroke, 42, S28-S32. https://doi.org/10.1161/STROKEAHA.110.596528

[37] Hong, J.M., Bang, O.Y., Chung, C.S., Joo, I.S. and Gwag, B.J. (2010) Ovbiagele B: Influence of Recanalization on Uric Acid Patterns in Acute Ischemic Stroke. Cerebrovascular Diseases, 29, 431-439. https://doi.org/10.1159/000289346 